\title{
The Risk Analysis and Evaluation of Urban Underground Logistics System Development Based on the Grey Analytic Hierarchy Process
}

\author{
Xiao Hong, Cheng Xiaoliang and Zou Cilan*
}

Department of Management, Chongqing Jiaotong University, Chongqing, 400074, China

\begin{abstract}
Urban underground logistics system is a newly emerging concept, and there is no molded sample project to provide reference information. So there exists much uncertainty in its development, and such uncertainty will have some impact on overall development of the system. In this paper, gray analytic hierarchy process analysis will be used to evaluate the risk factors in the development of urban underground logistics system. And then, we use the empirical analysis to quantify the risk of the development of urban underground logistics and provide references for the development of urban underground logistics system.
\end{abstract}

Keywords: Grey analytic hierarchy process, risk analysis, underground logistics system.

\section{INTRODUCTION}

Urban underground logistics system is used for transporting goods from outside of the edge of the city through various transportation means. These goods are then forwarded to the ULS (Underground Logistics System) and later transported to each customer from distribution centers, factories, and warehouses [1]. As a new system, ULS construction costs heavily therefore it is difficult to obtain adequate finance support. This promising venture investment project may lose development opportunities at the initial stage due to the lack of funding sources. If we could analyze and control the risk conditions more accurately during early development, then public as well as private sectors will support the rapid development of urban underground logistics systems.

Vernimmen Bert et al. (1990) envisaged the development of an underground logistics system which can solve the growing number of container transportation problems from the Port of Antwerp [2]. Zevgolis, et al. (2004) focused on the design of an underground Warehousing Logistics Center (WLC) in the wider metropolitan area of Athens. The center is developed using the room and pillar mining method. The main concept of the paper is that creating an underground space for a particular use is not enough, especially in countries attempting to develop their underground logistics systems [3]. The key point is to prove that such underground facilities can be as functional as a respective surface system, and the same time, are economically competitive. Verbraeck, et al. (2001) provided new concepts for logistic control of highly automated transport systems. The concepts are illustrated by examples from a large research project on highly automated transport system and the underground logistic system (OLS) [4]. Due to the rapid increase in urban logistics, many scholars have recommended the development of underground logistics systems. However, they have not analyzed the risks involved in developing an underground logistics system. Because of the lack of research, many scholars have used the gray analytic hierarchy process for studying the ULS. We have proposed the G-AHP method for analyzing the feasibility of developing an underground logistics system.

\section{URBAN UNDERGROUND LOGISTICS AND DEVELOPMENT RISKS}

On the basis of summarizing various risks factors, Zhu Shuzhen (2002) has defined the risk as the possibility of losses as a result of many uncertainties under specific conditions and at specific periods of time. Risk is defined as a two-bit concept, and measured with the size and probability of loss. Wang mingtao (2003) defined risk as the possibility of an unfavorable outcome and the extent of losses within a certain time among the decision-making process, due to the presence of various uncertainties. It includes three aspects which contain the probability of loss, the scale of possible loss and the variability. The scale of the loss may be considered as the most important factor.

Theoretically, the risk in the development of urban underground logistics system can be reduced by risk management measures, but it cannot be completely eliminated because it is mainly generated by the project itself. The causes of risk development mainly include the following aspects:

\subsection{The Limit of Cognitive Ability}

As a new concept, people lack a variety of comprehensive data and information for considering and predicting the future developments and changes in the ULS. Because of cognitive inability, people can't break through the depth and breadth limits, making it impossible to obtain complete information of the project and avoid potential risks [5]. 


\subsection{The Lag of Information}

Any project which is based on the past and incomplete information result in a variety of potential risk factors in the project. Being an important part of project development and management, the data and information should be regularly updated till the final completion of the logistics system. It will help people in obtaining complete project information. Hence it can be said that the information lag is a risk factor for the project.

\subsection{The Uncertainty of Environment}

During the development of ULS, we may encounter internal and external changes. Once a change occurs in the environment, the system will also change accordingly which would bring a lot of uncertainty to the project development. Such uncertainty is an important risk factor for the development of urban underground logistics. Project risk analysis allows us to take advantage of intuitive evaluation project feasibility. If the risk analysis indexes are high, the project development will face great risks. This paper focuses on using the G-AHP model for analyzing the developmental risks in the urban underground logistics systems. The final analyses results verify that the feasibility of project development is greatly affected by environmental uncertainties.

\section{GREY ANALYTIC HIERARCHY PROCESS EVALUATION MODEL}

\subsection{The Establishment of Risk Evaluation Index System}

According to the key factors which are the main sources and essential characteristics of risks, we established the principles of the urban underground logistics system integrated risk. The risk evaluation index system is set up and shown in Fig. (1). The index system has three levels: the goal layer, the factor layer and the index layer [6]. The goal layer is comprehensive risk of underground logistics system, the factor layer refers to all aspects of the impact and the index layer contains the detailed and refined indicators which react to each risk factor accordingly [5]. We designed such an index system for describing and evaluating the general risks for underground logistics system in which all important aspects are considered.

\subsection{Determine the Weight of Evaluation Index and the Evaluation Matrix}

Each indicator of the index system has its own different influence on the target. While measuring the role of each indicator, we should give different weights to these indicators according to the target. The more important of the indicator, the higher its weight. In the G-AHP model, with Analytic Hierarchy Process we use data consistency test on urban underground logistics system risk assessment index system to determine whether the index weight is reasonable [7].

$$
\mathrm{D}=\left[\begin{array}{cccc}
d_{111} & d_{112} & \ldots & d_{11 n} \\
d_{121} & d_{122} & \ldots & d_{12 n} \\
\vdots & \vdots & \vdots & \vdots \\
d_{211} & d_{212} & \ldots & d_{21 n} \\
\vdots & \vdots & \vdots & \vdots \\
d_{p q 1} & d_{p q 2} & \ldots & d_{p q n}
\end{array}\right]
$$

$d_{p q n}$ - Scores which the $n$ expert gives based on the $P$ risk factor layer and $Q$ risk index layer.

Table 1. The index system of risk elevation of underground logistics system.

\begin{tabular}{|c|c|c|}
\hline $\begin{array}{c}\text { Goal } \\
\text { Layer }\end{array}$ & Factor Layer & Index Layer \\
\hline \multirow{15}{*}{  } & \multirow{3}{*}{$\begin{array}{l}\text { Technical } \\
\text { risk } U_{1}\end{array}$} & Technical reliability $\mathrm{U}_{11}$ \\
\hline & & Technical applicability $\mathrm{U}_{12}$ \\
\hline & & Technology advanced $U_{13}$ \\
\hline & \multirow{3}{*}{$\begin{array}{l}\text { Operational } \\
\text { risk } U_{2}\end{array}$} & Energy supply $\mathrm{U}_{21}$ \\
\hline & & City infrastructure $\mathrm{U}_{22}$ \\
\hline & & Industry association $U_{23}$ \\
\hline & \multirow{3}{*}{$\begin{array}{l}\text { Human } \\
\text { resource } \\
\text { risk } U_{3}\end{array}$} & Supply of ordinary workers $U_{31}$ \\
\hline & & High-quality professional talent supply $\mathrm{U}_{32}$ \\
\hline & & The project sponsor's quality $\mathrm{U}_{33}$ \\
\hline & \multirow{4}{*}{$\begin{array}{l}\text { Environmental } \\
\text { risk } U_{4}\end{array}$} & Social and political situation $\mathrm{U}_{41}$ \\
\hline & & Financial and capital market conditions $\mathrm{U}_{42}$ \\
\hline & & Policy and law risk $\mathrm{U}_{43}$ \\
\hline & & Public support status $U_{44}$ \\
\hline & \multirow{2}{*}{ Policy risk $\mathrm{U}_{5}$} & Socio-political situation $\mathrm{U}_{51}$ \\
\hline & & Risk policies and regulations $\mathrm{U}_{52}$ \\
\hline
\end{tabular}

\subsection{Determine the Evaluation of Grey and Grey Evaluation Coefficient}

In order to reflect the influence degree of risk objectively, the risk evaluation grey of engineering project needs to be determined. These are the evaluation grey level, grey number and the whitenization weight function [7, 8]. The evaluation grey is divided into low, fairly low, normal, fairly high and high five degrees, the superiority is described by e $(e=1,2,3,4,5)[9]$. The whitenization weight function is selected to be linear. The whitenization weight functions corresponding to grey number are shown as follows [10]:

set $X_{1}=1, X_{2}=2, X_{3}=3, X_{4}=4, X_{5}=5$.

(1) low $\operatorname{risk}\left(\mathrm{e}=1\right.$, grey number $\otimes_{1} \in[0,1,2]$, the Whitenization weight function $f_{1}$ is

$f_{1}\left(d_{p q n}\right)= \begin{cases}1 & d_{p q n} \in[0,1] \\ 2-d_{p q n} & d_{p q n} \in[1,2] \\ 0 & d_{p q n} \notin[0,2]\end{cases}$

Similarly we can get the whitenization weight function $f_{2}, f_{3}, f_{4}$. rey number $\otimes_{5} \in[0,5,10]$, the Whitenization weight function $f_{5}$ is:

$$
f_{5}\left(d_{p q n}\right)=\left\{\begin{array}{lc}
d_{p q n} / 5 & d_{p q n} \in[0,5] \\
1 & d_{p q n} \in[5,10] \\
0 & d_{p q n} \notin[0,10]
\end{array}\right.
$$


For the index of project risk evaluation $U_{i j}$, the grey evaluation coefficient of the assessed risk factor of the e evaluation grey is $\mathrm{M}_{\mathrm{ije}}$ :

$$
M_{i j e}=\sum_{k=1}^{m} f_{e}\left(d_{p q n}\right)
$$

Then the grey evaluation coefficients of belonging to the other e can be regarded as $\mathrm{M}_{\mathrm{ij}}$ :

$$
M_{i j}=\sum_{e=1}^{5} M_{i j e}
$$

For the evaluation index $U_{i j}$, all the evaluators' grey evaluation weight of project's e grey evaluation is $r_{i j e}$,

$$
r_{i j e}=M_{i j e} / M_{i j}
$$

For the evaluation project's grey evaluation weight vector $r_{i j}, r_{i j}=\left|r_{i j 1}, r_{i j 2}, r_{i j 3}, r_{i j 4}\right|$, then we get the gray evaluation weight matrix $R_{i}$ of risk evaluation index $U_{i j}$ :

$$
R_{i}=\left[\begin{array}{c}
r_{i 1} \\
r_{i 2} \\
r_{i 3} \\
\vdots \\
r_{i j}
\end{array}\right]=\left[\begin{array}{ccccc}
r_{i 11} & r_{i 12} & r_{i 13} & \ldots & r_{i 1 m} \\
r_{i 21} & r_{i 22} & r_{i 23} & \ldots & r_{i 2 m} \\
r_{i 31} & r_{i 32} & r_{i 33} & \ldots & r_{i 3 m} \\
\vdots & \vdots & \vdots & \ddots & \vdots \\
r_{i j 1} & r_{i j 2} & r_{i j 3} & \ldots & r_{i j m}
\end{array}\right]
$$

\subsection{Calculate the Comprehensive Analysis Value}

(1) Calculate the comprehensive evaluation of the second risk factor layer $U_{i j}$ and record it as $B_{i}$. The calculation formula follows:

$B_{i}=A_{i} \cdot R_{i}$

(2) The calculation results of the first risk factor layer $U_{i}$ are recorded as $\mathrm{B}$, which can be calculated by the following formula:

$B=A \cdot B_{i}$

(3) This paper introduces 5 levels of gray value, and they are $1,3,5,7,9$ respectively. So the grey level value vector $C=(1,3,5,7,9)$, the evaluation value of the project's general goal is:

$Z=B \cdot C^{T}$

According to the value of $\mathrm{Z}$, we can determine the rating of risk and take appropriate measures to process and control the risk scientifically.

\section{NUMERICAL EXAMPLE}

Taking the development of urban ULS project in Shanghai as an example, we can use the G-AHP method above to analyze the project risk. Firstly we invite 5 experts to score the first and second risk factor layer and then get the judgment matrix. After processing the data, the comprehensive judgment matrix is obtained, and then use the AHP to determine the weight vector of first layer evaluation index: $A=(0.51,0.08,0.26,0.15)$; and the weight vectors of second layer evaluation index $\operatorname{are}_{1}=(0.13,0.59,0.28)$,
$\mathrm{A}_{2}=(0.18,0.71,0.11), \mathrm{A}_{3}=(0.09,0.29,0.62),{ }_{4}=(0.11,0.31,0.58)$. And the five experts will give scores to the second layer 12 indexes in the index system and then we get the evaluation of sample matrix:

$D^{T}$

$=\left[\begin{array}{lllllllllllllll}5 & 5 & 4 & 2 & 4 & 8 & 2 & 6 & 6 & 7 & 4 & 8 & 3 & 2 & 3 \\ 8 & 5 & 6 & 2 & 3 & 7 & 2 & 7 & 4 & 6 & 3 & 6 & 1 & 1 & 5 \\ 4 & 6 & 6 & 2 & 6 & 9 & 1 & 7 & 8 & 6 & 3 & 8 & 2 & 3 & 4 \\ 7 & 6 & 5 & 1 & 5 & 8 & 2 & 6 & 6 & 5 & 3 & 9 & 2 & 3 & 3 \\ 6 & 7 & 6 & 3 & 6 & 8 & 1 & 8 & 8 & 5 & 2 & 7 & 2 & 2 & 3\end{array}\right]$

For the first evaluation index technology reliability $U_{11}$, the calculation process of its evaluation coefficient is as follows: calculate the risk coefficients $M_{\mathrm{ije}}$ of different e firstly.

$\mathrm{e}=1: M_{111}=f_{1}\left(d_{111}\right)+f_{1}\left(d_{112}\right)+f_{1}\left(d_{113}\right)+f_{1}\left(d_{114}\right)+$
$f_{1}\left(d_{115}\right)=0$
$\mathrm{e}=2: M_{112}=$
$f_{2}\left(d_{111}\right)+f_{2}\left(d_{112}\right)+f_{2}\left(d_{113}\right)+f_{2}\left(d_{114}\right)+f_{2}\left(d_{115}\right)=0$
$\mathrm{e}=3: M_{113}=$
$f_{3}\left(d_{111}\right)+f_{3}\left(d_{112}\right)+f_{3}\left(d_{113}\right)+f_{3}\left(d_{114}\right)+f_{3}\left(d_{115}\right)=1$
$\mathrm{e}=4: M_{114}=f_{4}\left(d_{111}\right)+f_{4}\left(d_{112}\right)+f_{4}\left(d_{113}\right)+f_{4}\left(d_{114}\right)+$
$f_{4}\left(d_{115}\right)=2.5$
$\mathrm{e}=5: M_{115}=$
$f_{5}\left(d_{111}\right)+f_{5}\left(d_{112}\right)+f_{5}\left(d_{113}\right)+f_{5}\left(d_{114}\right)+f_{5}\left(d_{115}\right)=4.8$

Therefore, the general evaluation coefficient $M_{11}$ :

$M_{11}=M_{111}+M_{112}+M_{113}+M_{114}+M_{115}=8.3$

The gray evaluation weight is recorded as $r_{\mathrm{ije}}$ :

Trough calculation we can get $r_{111}=0 ; r_{112}=0 ; r_{113}=0.12$ $; r_{114}=0.30 ; r_{115}=0.58$

The grey evaluation weight vector of technology reliability risk is $r_{11}$ :

$$
\begin{aligned}
r_{11}=\left(r_{111}, r_{112},\right. & \left.r_{113}, r_{114}, r_{115}\right) \\
= & (0,0,0.12,0.3,0.58)
\end{aligned}
$$

Similarly, the general evaluation coefficient of other 11 indexes can be calculated at the same method, named as $r_{12}$, $r_{13}, r_{21}, r_{22}, r_{23}, r_{31}, r_{32}, r_{33}, r_{41}, r_{42}, r_{43}, r_{44}$, $r_{51}, r_{52}$. So the grey evaluation matrixes of second layer are:

$$
\begin{aligned}
R_{1} & =\left[\begin{array}{lllll}
0.00 & 0.00 & 0.12 & 0.30 & 0.58 \\
0.00 & 0.00 & 0.08 & 0.33 & 0.59 \\
0.00 & 0.00 & 0.11 & 0.36 & 0.53
\end{array}\right] \\
R_{2} & =\left[\begin{array}{lllll}
0.08 & 0.31 & 0.26 & 0.19 & 0.16 \\
0.00 & 0.05 & 0.19 & 0.34 & 0.42 \\
0.00 & 0.00 & 0.00 & 0.05 & 0.95
\end{array}\right]
\end{aligned}
$$$$
R_{3}=\left[\begin{array}{lllll}
0.16 & 0.33 & 0.22 & 0.16 & 0.13 \\
0.00 & 0.00 & 0.00 & 0.23 & 0.77 \\
0.00 & 0.00 & 0.09 & 0.27 & 0.64
\end{array}\right]
$$$$
\left[\begin{array}{lllll}
0.00 & 0.00 & 0.08 & 0.33 & 0.59
\end{array}\right]
$$

$$
\left[\begin{array}{lllll}
0.08 & 0.31 & 0.26 & 0.19 & 0.16
\end{array}\right]
$$$$
R_{5}=\left[\begin{array}{lllll}
0.08 & 0.26 & 0.28 & 0.21 & 0.17 \\
0.00 & 0.11 & 0.31 & 0.31 & 0.27
\end{array}\right]
$$ 


$$
\begin{gathered}
\text { According to formulas } \\
\mathrm{B}=(0.01,0.04,0.11,0.20,0.57)
\end{gathered}
$$

and

The overall goal $\mathrm{Z}$ of the project risk evaluation can be calculated according the formula (9):

$$
\mathrm{Z}=\left(\begin{array}{lllll}
0.01 & 0.04 & 0.11 & 0.20 & 0.57
\end{array}\right)\left(\begin{array}{llll}
1 & 3 & 5 & 79
\end{array}\right)^{T}=7.21
$$

Thanks to the gray analytic hierarchy mode, we can elevate the project risk of ULS and qualify the risk with general elevation value 7.21. In accordance with the value of 1-10 grades assess requirements, 7.21 belongs to a higher risk. Risk managers should analyze the risk further combining with the actual risk level of project and identify sources of high risk to make sure that the project be controlled at a low level of risk [11].

\section{CONCLUSION}

As a new system, urban underground logistics construction is difficult to get support without scientific and reasonable risk investment analysis. If we can predict the risk level more accurately before the investment and control it effectively during the construction process, more support will be attracted from enterprises and the government which will greatly contribute to its development. This paper uses the gray level analysis method, and combines the advantages of AHP with gray system. The qualitative and quantitative analysis can significantly reduce the subjective factors of risk analysis, and improve the accuracy and validity of evaluation. In addition, the internal and external environment of the underground logistics system project is constantly changing; therefore the actual application and completion of the risk assessment should be the theme of future research.

\section{CONFLICT OF INTEREST}

The authors confirm that this article content has no conflict of interest.

\section{ACKNOWLEDGEMENTS}

Declared none.

\section{REFERENCES}

[1] Z.j. Ma, "Urban underground logistics system and its design", $J$. Log. Techno., 10, 12-15, 2004.

[2] V. Bert., D. Wout, G. Erik, and N. Theo, "Underground Logistics Systems: A Way to cope with growing internal container traffic in the port of antwerp?", J. Trans. Pla. Techno, 30, 391-416.

[3] E. Zevgolis, A.A. Mavrikos and D.C. Kaliampakos, "Construction, storage capacity and economics of an underground warehousing logistics center in Athens, Greece", J. Tunnelling and Underground Space Techno., 19, 165-173, 2004.

[4] A. Verbraeck, and C. Versteegt, "Logistic control for fully automated large scale freight transport systems; event based control for the underground logistic system", Schiphol. J. Int. Trans. Sys., 768-773, 2001.

[5] Q.H. Qian, and D.J. Guo., "An introduction to the city underground logistics system”. J.CHN Com. 2007 Press.

[6] X. Deng, J.M. Li, H.J. Zeng, J.Y. Chen and J.F. Zhao, "Analytic hierarchy process weight calculation method for the analysis and application research", J. Math. Pra. Theo., 2012.

[7] J.Q. Liang, and S.G. Liu, "Multi-level gray comprehensive evaluation method in the port construction project risk evaluation", CHN Water Trans, 2011.

[8] J.C. Cai, Y. Wang, and H.L. Li, "Grey hierarchy evaluation for investment risk of venture capitial”, J. Ind. Eng. Man., 94-97, 2003.

[9] A. Samvedi, V. Jain and T.S. Chan. Felix, "An integrated approach for machine tool selection using fuzzy analytical hierarchy process and grey relational analysis", Int. J. Pro. Res., 50, 3211-3221, 2012.

[10] J.H. Boykin, A. A. Ring, "The valuation of real estate," Rogenss Prentiee Hall, 1993.

[11] Z. Srdjevic, M. Lakicevic, "Approach of decision making based on the analytic hierarchy process for urban landscape management", $J$. Env. Manage., 51, 777-785, 2013. 